\title{
Health outcomes of the July 14, 2016 Nice terror attack among hospital-based professionals and students: the «ECHOS de Nice » health survey protocol
}

Laurence Bentz $^{1 *}$ (D), Philippe Pirard ${ }^{2,3}$, Yvon Motreff ${ }^{2,4}$, Stéphanie Vandentorren ${ }^{5,4}$, Thierry Baubet ${ }^{3,6,7}$, Roxane Fabre ${ }^{1,8}$, Pia Touboul Lundgren ${ }^{1}$ and Christian Pradier $^{1}$

\begin{abstract}
Background: The terror attack of July 14, 2016, in Nice, France, resulted in 86 deaths, including children, and several hundred wounded, with a major psychological impact on the population. Hospital staff had to cope with exceptional circumstances which made them vulnerable to detrimental effects on their own health.

This paper describes the method that was selected for the survey entitled "ECHOS de Nice 14 Juillet" which aimed to assess the impact of the attack on the psychological, psycho-traumatic and somatic health condition of the Nice University and Lenval hospital staff who were directly or indirectly exposed to the attack, and also to describe the support and care facilities they were offered.

Method: ECHOS de Nice 14 juillet is an observational, cross-sectional, multicentre study focusing on all the hospital staff and students of both institutions, i.e. 10,100 persons in June 2017. A web-based questionnaire based on the model developed by Santé Publique France (IMPACTS and ESPA 13 novembre 2015) was adapted to the contexts of the healthcare professionals and students employed in these healthcare institutions in Nice and published on line from June 21 to October 30, 2017. The paper describes the tools that were used to meet the aims of the study, i.e. identification of exposure categories ('civilian' exposure for those present during the attack and/or 'professional' exposure); indicators of psychological impact (anxiety, depression, burnout, compassion fatigue, suicidal states, tobacco and alcohol use, self-medications), psycho-traumatic and somatic impact; professional and social impact. Lastly, awareness of availability and use of psychological support and care-follow-up facilities by professionals were investigated. Respondents could include extensive qualitative comments on the various themes explored in the questionnaire, with text analysis complementing that of quantitative data.
\end{abstract}

Discussion: The benefits and limitations of the selected methodology are discussed, in view of contributing useful information to help anticipate and manage health issues among hospital staff who have been victims of traumatic events.

Keywords: Terrorist attack, Hospital staff, Stress disorders, Post-traumatic, Needs assessment, Research design, Occupational health, Web questionnaire

\footnotetext{
*Correspondence: bentz.!@chu-nice.fr

${ }^{1}$ Public Health Department, Cote d'Azur University, Nice University Hospital,

F-06200 Nice, France

Full list of author information is available at the end of the article
}

(c) The Author(s). 2019 Open Access This article is distributed under the terms of the Creative Commons Attribution 4.0 International License (http://creativecommons.org/licenses/by/4.0/), which permits unrestricted use, distribution, and reproduction in any medium, provided you give appropriate credit to the original author(s) and the source, provide a link to the Creative Commons license, and indicate if changes were made. The Creative Commons Public Domain Dedication waiver (http://creativecommons.org/publicdomain/zero/1.0/) applies to the data made available in this article, unless otherwise stated. 


\section{Background}

The July 14, 2016 terror attack in Nice, during the Bastille day fireworks, when a lorry rammed into the crowd, resulted in many victims among the civilian population: 86 dead, among whom 10 children and adolescents, and 434 wounded [1]. Thousands were involved in the event. A great number of healthcare professionals from all staff categories were also directly affected by the attack: either on the site of the attack as civilians attending the fireworks, or as hospital healthcare professionals taking charge of the victims and/or their families. Two healthcare institutions were involved in the immediate aftermath of the event and the long-term follow-up of victims: the Lenval paediatric hospital which was the first institution to admit both children and adult victims, and the Nice University hospital. In such a context, healthcare professionals were faced with particularly challenging circumstances, with a major influx of victims both living and deceased, including children, severe injuries [2], exceptional clinical and psychological management procedures for victims and their families, and the search for those missing [3].

This type of event places healthcare professionals from the institutions at risk of developing psychological and/ or somatic disorders related to the event. Compared to natural or technological causes, intentional mass violence has been shown to have an even greater impact on populations in terms of psychological distress [4]. Repercussions may be felt in many areas of daily life, affecting professional, family and social functioning [5].

To our knowledge, few studies have focused specifically on health outcomes among hospital staff and their care and support-seeking practices in the aftermath of the event.

Regarding the psychological component, this type of event can induce depression-related anxiety disorders [6-10], panic attacks [11], and suicidal thoughts, behaviours and/or fatalities among care-providers [12-14].

Caregivers may also develop post-traumatic stress disorder (PTSD) which is defined in adults by a range of criteria [15]. The first of these is exposure to a traumatic event that occurred outside the scope of usual human experience $[16,17]$. Diagnostic criteria for PTSD include those related to the exposure (criteria A1 to A4) and those related to the presence of four symptom categories (criteria B to E) associated with the traumatic event and arising within the first month following the event. Patients may also display dissociative features (depersonalisation, derealisation). In PTSD, these disorders last for more than a month $[15,18,19]$, and may progress to chronic PTSD when symptoms persist beyond 3 months [15]. Onset of PTSD may be delayed, i.e. full diagnostic criteria are not met until at least 6 months after the trauma(s), although onset of symptoms may occur immediately
[15]. These disturbances cause clinically significant distress or impairment in social, occupational or family or other important areas of functioning and are not attributable to other causes than trauma exposure $[15,18,19]$.

Such consequences vary according to participants' occupation. Strong variations in prevalence of PTSD are described in the literature according to the type of occupational and exposure situations. [20]. In the immediate aftermath of attacks or mass shootings, on-site rescue workers are the first to intervene: prevalence rates among these rescuers ranges from 0.4 to $22.0 \%$ [21-25]. Among rescuers who were health professionals involved in the November 2015 terrorist attack in Paris, the observed prevalence rate was $4.5 \%$ [10]. These studies thus confirm that first responders and/or rescue or recovery workers are at high risk for PTSD [26], but prevalence rates are not sufficiently documented for health professionals who intervene at a later stage of the care process, and more broadly, for hospital staff.

Furthermore, specific types of professional traumatic events and associated levels of exposure are still not established [27]. In the context of the Nice terror attack, exposure among professionals from Nice University and Lenval hospitals included confronting an exceptionally stressful environment, with a major influx of victims both living and deceased and a number of tasks widely exceeding their usual work situations [28]. Health professionals were exposed either directly (primary trauma, through their presence on the site of the attack; or according to the type of management procedures that may be considered as trauma) or indirectly, through secondary exposure to individuals (victims, family members or colleagues) who had witnessed highly stressful or traumatising events (vicarious trauma). Trauma related to hospital work can be considered a combination of primary and secondary trauma [29].

Although full PTSD-defining B-E criteria may not be systematically present in trauma victims, symptoms can be a source of distress. This has been characterised as sub-threshold PTSD [30]. The prevalence rate thus ranges from 8 to $24 \%$ according to the population under study [24, 31-34]. As these sub-threshold conditions may be clinically significant and result in incapacitating social, professional and functional impairment [35], they should therefore be identified and taken into account so that therapeutic assistance can be offered to those with these conditions.

Healthcare professionals are at risk for compassion fatigue. This exclusively concerns professionals involved in various forms of assistance (first aid professionals, clinicians, social workers ...) [36]. The term refers to symptoms which appear to result from exposure to the difficulties confronted by patients and the permanent burden of the empathy they require. Thus, the 
compassion fatigue that healthcare professionals may experience includes burnout and secondary traumatic stress (vicarious trauma) [29]. Secondary traumatic stress results from secondary exposure of professionals to individuals who have lived through highly stressful or traumatising events. In such circumstances, it can lead to sleep disturbance, intrusive images, avoiding reminders of the patient's traumatic experience. Although most studies on this syndrome have focused on clinicians treating psychological trauma among survivors [37], this syndrome has been identified for several years among therapists working with victims and their families [36, 37].

Increased use of tobacco, alcohol and marijuana may be related to the psychological outcomes linked to a terrorist attack, sometimes over a prolonged period [38]. These types of substance use were also found to be associated with depression or PTSD [39]. They have been identified among a significant proportion of agents who had worked on the World Trade Centre site [40] or among Norwegian rescuers who intervened in 2011 [41]. Such increased use was confirmed in the first 2 years following a terrorist event [42].

Besides the consequences at the professional level, a disaster may also have a negative somatic impact $[6,7]$. Following terrorist attacks, somatic disorders were observed among rescuers in the form of heart disease [43, 44], arising in various contexts [40, 41]. More specifically, patients presenting with PTSD have a significantly higher risk of developing diabetes [45], sleep disturbances [46], cardiac and auto-immune disorders [7, 47, 48].

Repercussions on care-givers can be experienced in all aspects of life, including in the social and family environment [49]. Physicians in London suffering from multiple co-morbidities (depression, alcohol abuse, anxiety and self-medication) described greater difficulties in adapting to daily life, with repercussions on their professional activity [5].

However, when care programmes are implemented, follow-up has a positive impact on both social and professional capacities, making it possible to resume work [50]. In the IMPACTS study, just over half the protagonists received medical and psychological care in the aftermath of the attacks, mostly within their institution. [9]. It is thus worth investigating, as a complement to exploring psychological and somatic repercussions, the awareness and use of hospital support facilities that are provided in the aftermath of a terror attack.

The objective of this paper is to describe the method that was selected for the ECHOS de Nice 14 juillet study which aimed to estimate the impact of the terror attack on the psychological, psycho-traumatic and somatic health of hospital staff and students at Nice University and Lenval hospitals who were directly or indirectly exposed to the July 14th attack, and to describe hospital professionals' use and needs regarding support and care facilities.

\section{Methods/design \\ Study design}

This was a cross-sectional, multicentre, observational study.

\section{Study population}

The study focused on all hospital staff and students above 18 years of age registered with Nice university and Lenval hospitals from July 13, 2016, whether directly or indirectly involved in the terror attack of July 14, 2016. Overall, 10, 100 subjects were registered on the Human Resources Departments' lists of both hospitals in June 2017.

\section{Non-inclusion criteria}

Those below 18 years of age when completing the questionnaire, as well as those not or no longer employed as hospital staff, medical students and residents, or paramedical students by the institutions concerned between July 2016 and the beginning of the study.

\section{Study period}

Participants were asked to complete a secured web-questionnaire available online from June 21 to October 30, 2017.

\section{Ethical considerations - informed consent - IT security} The study was registered with the French Data Protection Authority under $\mathrm{N}^{\circ} 270$ and with the Ethics Committee (CPP Nord ouest III, Caen, France) under $\mathrm{N}^{\circ}$ ID RCB: 2017-A00812-51. Specific measures were implemented to guarantee IT security of collected data. The implementation process of the ECHOS de Nice web questionnaire was identical to that of a study focusing on victims of the November 2015 terror attack (ESPA 13 novembre) $[10,51]$ which had been subjected to an external security audit.

Information regarding the objectives and the procedures related to the survey were available on the intranet sites of both institutions. A letter was attached to the payslip of each member of staff in June 2017. Specific communication activities were conducted among the teams of various departments and staff representatives.

Access to the website also facilitated access to information on psychological trauma and its determinants. [http://invs.santepubliquefrance.fr/Dossiers-thematiques/ Populations-et-sante/Actes-terroristes].

Lastly, the questionnaire gave details of psychological support facilities available within the institutions (helpline, secretarial office hours for making appointments). Medical students were informed that they could request support via an email address. All respondents who 
wished to provide contact details in order to be contacted by a psychologist specialised in psychological trauma could do so, and a hotline was also established to enable them to call the specialist directly.

Lastly, inclusion data and survey data were stored in separate databases.

\section{Web-based questionnaire}

The questionnaire was specifically adapted for health professionals and students employed in health institutions in the Nice context. To take health-related literacy into account, particular care was given to the wording of the questions to facilitate their comprehension [52]. The questionnaire was pilot-tested on the various categories of professionals from several hospital departments, with varying degrees of exposure to the attack, to record their comments and suggestions for change. Filters were developed in such a way that questions were adapted to the respondent's situation (hospital staff or student, involved or not in the attack and its aftermath). Completing the questionnaire was estimated to require approximately 20 to $45 \mathrm{~min}$.

\section{Collected data}

\section{Socio-demographic and professional information}

The psychological and somatic disorders resulting from the terror attack among involved members of staff were analysed according to age and gender, institution and department of activity at the time of the attack (Nice university and Lenval hospitals), years of professional experience, professional category (as described by the Human Resources department, i.e. medical, caregiver, administration, logistics/technical, medico-technical, socio-educational staff).

The impact may indeed differ according to the professional category of exposed professionals, (e.g. nurses, doctors, [53], psychologists [54], ambulance staff) $[55,56]$. It may also vary according to the hospital department with potentially severe psychological repercussions among rescue workers or emergency department staff who are regularly faced with traumatic events in their professional environment. [21, 56-58]. These repercussions may also result from an exceptional exposure of members of staff usually less liable to be confronted with such situations and less trained in the management of psycho-social risks (e.g. ambulance staff).

These socio-demographic characteristics contribute to the analysis of known risk or protective health-related factors. Namely, it will thus be possible to compare levels of PTSD with published data according to professional categories and to measure their correlation with the level of exposure and other determinants.

\section{Circumstances and degree of trauma exposure}

Collected data included site of exposure (on-site or at a later stage), sensory exposure (according to the definition of trauma which always results from a perception or sensation, i.e. having seen, heard, smelt), [59], the timing of professional intervention (early intervention on the attack site for rescue staff, and/or intervention within the hospital departments) [60], the nature of professional tasks performed in relation to the circumstances of the attack. A description of acute stress [61] and/or peritraumatic experience at some point during exposure [62] were considered risk factors for PTSD [63].

\section{Professional tasks performed by hospital staff}

Exposed professionals were questioned on the circumstances of their professional intervention. Professional tasks were grouped into three major categories:

- Tasks related to living or dead bodies (clinical, surgical, forensic, but also transportation of living or deceased victims, X-rays of bodies or body parts, cleaning, forensic activities ...).

- Tasks related to the psychological management of victims and families, informing families of deceased victims, communicating and supporting persons in distress (comforting, hosting, translating for foreign families); support for distressed professionals and students.

- Tasks related to crisis management (triggering the emergency plan, ...), processing of phone calls for emergency services, management of operational hospital back-up (technical, logistical), identification and follow-up of victims during the course of their care pathway, administrative or logistic details (update and follow-up of records for those in care, etc. ...).

Other questions focused on familiarity with the professional procedures undertaken and/or whether these tasks were part of usual duties; prior training before they were performed; circumstances giving rise to special difficulties when performing professional tasks. All these items were liable to compound the impact of professional exposure.

\section{Staff exposure categories}

Staff exposure was categorized according to criterion A which contributes to the definition of PTSD in adults [15]. Criterion A identifies the trigger to PTSD as exposure of an individual to threatened death, severe injury or " first-hand repeated or extreme exposure to aversive details of the traumatic event ». This last situation may concern first-line rescuers gathering human remains. Aside from such specific circumstances, this exposure category may have applied to a wide range of situations 
and activities, including staff directly involved with victims, but also any professional category subjected to intense operational pressure.

According to circumstances of exposure, three groups were identified:

- Those members of staff exclusively involved: these were not present on the site of the attack but were involved during a specific stage of victim assistance or of institutional organisation in relation to assisting victims.

- Those having witnessed the attack, regardless of whether they were involved or not in assisting the victims.

- Those not exposed, nor having witnessed the attack and not involved in any stage of assistance to victims.

\section{Psychological impact indicators}

Anxiety and/or depression Hamilton developed a double rating scale (Hospital Anxiety and Depression scale, HAD) measuring the intensity of perception of seven symptoms indicative of anxiety (7 questions scoring 0 to 3 ) and of seven symptoms indicative of depression (7 questions scoring 0 to 3 ) during the previous week. The HAD scale, which has been approved for the general population, provides a screening tool for states of anxiety or depression (confirmed for a score above 9) that calls for specialist assessment [64-67].

Suicidal thoughts Persons exposed to the attack were asked whether the distress experienced since the attack had led to suicidal thoughts; if so, their delay of emergence; how these thoughts developed (fleeting ideation; frequent ideation without an intent; suicidal intent; programming a suicidal gesture; interrupted suicide attempt; suicide attempt); consultations because of these ideas; personal history of suicidal thoughts during the year before the attack, with or without hospitalization. Respondent's resort to medical help in relation with this issue was also investigated.

Compassion fatigue This breaks into two parts: [29].

The first part concerns reactions such as exhaustion, frustration, anger and depression typical of burnout or professional exhaustion [68].

The second part is a negative feeling driven by fear and work-related trauma, known as « secondary traumatic stress » or « vicarious trauma ». Burnout and secondary traumatic stress were detected and assessed using the ProQOL measurement tool which was developed to identify these issues among helpers [29]. A score of 57 and above indicates the significant presence of each of these symptoms and allows detection of probable anxiety or depression syndromes, respectively. The score is used as a basis for discussion during the clinical examination with the physician. Burnout, secondary traumatic stress, depression and post-traumatic stress syndrome are often combined [29].

Changes in tobacco, alcohol and marijuana use were also investigated among respondents, before and after the terror attack. Respondents were asked whether, since the attack, they had started consuming these substances; had increased, decreased or discontinued their consumption; had a stable consumption; had never started or had discontinued for several years.

Changes in medication following the attack were also explored (medication for sleep disturbances, fear or stress, depression), prior use being considered as a potential pretraumatic risk factor.

\section{Indicators of psycho-traumatic impact}

The presence of PTSD was explored on the basis of answers to the PCL5 (PTSD CheckList), which is a scale developed to assess the presence and intensity (from 0 to 4) of the 20 symptoms divided into four categories (criteria B to E) associated with the traumatic event and arising in its aftermath $[15,18,69-72]$ :

- Intrusive symptoms (criterion B),

- Avoidance of trauma-related stimuli after the trauma (criterion C),

- Negative alterations of cognition and mood (criterion D),

- Trauma-related arousal and reactivity alterations (criterion E).

The presence of probable PTSD was based on the analysis of symptom categories, of over 1 month's duration. (criterion F) [30]. For each item, a score of 2 or above is considered clinically significant, considering that a provisional diagnosis of PTSD can be made by treating each item rated 2 or higher as an approved symptom and then following the DSM-5 diagnostic rule which requires at a minimum: 1 element of criterion $\mathrm{B}, 1$ element of criterion C, 2 elements of criterion D and 2 elements of criterion E [69].

Respondents were also asked whether symptoms were associated with a stated handicap affecting daily functioning (in their professional, social, family environment) (criterion G) [15].

Sub-threshold PTSD Based on the most common definitions encountered in the literature, McLaughlin suggests defining this condition as applicable to respondents meeting two or three (but not all four) of DSM- 5 Criteria B, C, $\mathrm{D}$, or $\mathrm{E}$ as described above [30]. 
The questionnaire also explored risk and protective factors for PTSD both from the personal and professional perspectives

Pre-trauma factors to be considered included female gender [15], previous trauma exposure [16], prior use of psychoactive drugs [73], type of health-related profession which determine the type of tasks performed and may constitute risk factors for PTSD (emergency workers, paramedics, ambulance staff, etc ... ). Assessment of previous trauma exposure was declarative: respondents were asked whether they had previously been confronted with potentially life-threatening events, during which they felt brutally threatened, or their life endangered (serious accident, physical aggression, military combat or war, sexual contact in childhood with an older person, natural disaster, sexual assault or rape, etc.). It also conversely included an investigation of protective factors (physicians being sometimes considered more resilient than other professional categories) [23, 74], prior professional training in view of confronting a critical situation [8], particularly in A\&E departments where such situations are regularly encountered $[75,76]$. The ECHOS de Nice questionnaire thus included questions regarding awareness of psychosocial risks, identification of resource persons, awareness of psychological consequences after involvement in a traumatic event.

To investigate peri-traumatic factors, the level of exposure to the traumatic event was taken into account, with a higher degree of severity for professionals who were directly involved [74], the temporal and environmental circumstances of exposure: first responders, onsite rescuers [9, 24, 77-79] or secondary intervention within an institution [80], the level of environmental safety and the perceived safety level [53, 81], the development of acute stress disorder following exposure to the event [15], for which the Bracha scale provides a checklist by measuring the level of physical symptoms linked to adrenal activation (4 questions scoring 0 to 5) [61]. Lastly, peritraumatic dissociation and its subsequent persistence in the aftermath were explored. The peritraumatic dissociative experience scale was used [62], which measures dissociative experiences during the traumatic event and the following hours with 14 questions scoring from 1 to 5 . Those who experience a high degree of dissociation have a higher risk of developing PTSD, presumably because this reflects a defence mechanism when resilience capacity is exceeded in a context of highly intense exposure to a traumatic event. A score of 15 or above is considered to reveal significant dissociation [82].

Among post-traumatic factors, the perceived quality of social support in the aftermath of the traumatic event is a major protective factor $[9,10,82-84]$.

\section{Somatic impact indicators}

On a declarative basis, 13 somatic symptoms were explored in our study. For each symptom, respondents were asked whether they had suffered pain since the attack; if the symptoms were already present before the attack and if they had worsened since; if they were still affected at the time of the study.

\section{Indicators of psychosocial impact}

Professional impact Exposed health professionals were asked whether they were relieved from their post after their intervention and how they considered this decision, whether their state of health precluded further work or training, and what occupational accident notification or work stoppage prescriptions had been issued. Indeed, 6 months after the Paris November 2015 terror attack, 6\% of on-site rescuers stated they were unable to return to work [9]. Moreover, teams confronted with this type of situation were those with the highest turnover, as a proportion of their members chose to move to another department or institution [11].

Consequences on social life Particularly repercussions on families and especially children [3]. We used the Sheehan disability scale, which was developed to assess functional impairment in three inter-related domains: work/studies; social and family life. The respondent rates the extent to which each domain is impaired by his or her symptoms on a 10-point visual analogic scale [85].

In addition, respondents were also invited to state via a free text comment whether they thought that the experience they had lived through had an effect on their children, or their relationship with them, and in what way.

Request for institutional and/or social support and awareness of resource persons Assessment of social support was declarative. Respondents were asked whether they knew of "resource persons" in the institution likely to provide help with psychosocial risks and the level of social support received, on a scale of 1 to 5 ; whether in their personal entourage, there were persons on whom to rely in case of moral or emotional need, and/or of material need; more generally, whether they felt alone or not in life (with a gradation of 1 to 4 from 'very much alone' to 'very well supported').

\section{Awareness of the specialised support facilities provided in the context of the survey, and care follow-up}

Hospital managers and even physicians themselves may underestimate the effects of critical work-related incidents [11]. Screening for symptoms and subsequent follow-up should be systematically considered, particularly after a major traumatic event or repeated exposure to stress $[58,76,86,87]$. 
In 2017, implementation of the ECHOS de Nice survey made it possible to outline hospital personnel care pathways. Since the web questionnaire might give rise to a revival of traumatic events in certain respondents, new support facilities were offered. At the end of the questionnaire, participants who " might feel the need for psychological assistance " were asked if they would " agree to have an interview with a specialist in psychotraumatic stress ». In case of an affirmative reply, they were asked if they agreed to be contacted and then to provide their contact details. The Nice University Hospital Public Health department was responsible for managing these requests on an entirely confidential basis. The Nice University Hospital Human Resources department allocated time for a clinical psychologist specifically trained in psycho-trauma to contact respondents from the CHU and Lenval hospitals who had expressed this need and to offer an appointment for specialized management according to their needs assessment.

The survey aimed to determine the proportion of staff members who accessed psychological support and care follow-up, particularly those respondents whose mental health was affected and who required appropriate management $[51,88]$. The medical profession is notoriously reluctant to consult, particularly regarding matters relating to mental health [89-92].

\section{Statistical analysis}

Qualitative data were described using mean and standard deviation, and qualitative data were described using frequency and percentage. Comparisons between the different groups were made using the Student or ANOVA test for quantitative variables, and using the Chi2 test or Fisher's exact test for qualitative variables. A $p$-value $<0.05$ was considered significant.

A multivariate analysis was performed using logistic regression. Factors with a $p$-value $<0.20$ in the univariate analysis were retained for model construction. Variables with a $p$-value $<0.05$ were retained. $95 \%$ confidence intervals were provided. Statistical analyses were performed using the SAS Enterprise Guide 7.1 software.

\section{Free-text comments}

The experience gained from the IMPACTS and ESPA 13 novembre studies illustrated the significant need of respondents to freely express themselves on various themes related to the attack and their substantial contribution in doing so. Based on this experience, the ECHOS de Nice questionnaire offered broader space for free comments which could be added for all the topics addressed: circumstances of exposure and memorable features, personal experience with consequences relating to several aspects of daily life (implying relationships with children), psychological and behavioural changes, circumstances of psychological support, level of satisfaction and suggestions for improving such support, acknowledgement of completed tasks by the institution. In particular, free comments pertaining to care follow-up may provide clues for improving the quality of services offered to professionals confronted with disasters or complex emergency situations [93].

\section{Discussion}

To our knowledge, few studies focusing on the repercussions on hospital staff of a terror attack have been published to date. Luce et al. studied the consequences of the Omagh bomb attack in Ireland on hospital personnel in terms of risk of PTSD [74]. Publications have also described the effects experienced by hospital staff in the context of war, e.g. the Gaza war [53], or missile strikes targeting a hospital [81] or in the context of a critical incident [11]. The impact of the 2015 Paris attacks on medical and psychological support teams $[9,25]$ was reported in recent publications, and more specifically on health professionals, including hospital, emergency psychological and medical services staff [10,26], who intervened in the 13 November 2015 attack. Our study concerns all hospital departments, regardless of staff category.

Due to the unpredictable character of the event, research focusing on the consequences of broad-scale traumatic events has two distinctive features: studies are observational by nature, and assessments are conducted after the occurrence of the event (post-only designs), which restricts the possibility of ruling out pre-existing symptoms or previous exposures, thus potentially compromising study findings and confounding symptom reports with exposure levels [94].

The second characteristic relates to the necessity of rapidly designing and implementing the survey to limit recall bias [77], which constitutes an organisational challenge for research teams [94]. Although we relied on the expertise acquired by Santé Publique France during the Paris attacks $[9,10,51]$, our survey began 11 months after the Nice attack. There were several reasons for this delay: tailoring the questionnaire to the specific context of a hospital institution, with multiple professional categories, various professional circumstances of exposure, testing and validating the model on a sample of hospital staff. Moreover, the study was conducted in two institutions, Nice University Hospital and Fondation Lenval, which required the involvement of several management and administration departments, and thus the necessary time for its implementation. Time was also required to obtain approval from the Ethics Committee [95]. Lastly, a communication strategy was developed and deployed towards the staff prior to initiating the study, encouraging participation and specifying the neutral and objective character of the study. 
Such a delay may have led to recall bias, and changes in symptoms over time. Conversely, it may have had positive consequences: PTSD identified 11 to 15 months after the attack revealed chronic $[48,96]$ or delayed PTSD [15], offering the possibility to compare symptom prevalence rates among staff in Nice with those observed among those in Paris $[10,25]$. The delay is also potentially useful to reveal professionals' registration for care follow-up.

Constraints related to delay and cost also contributed to the choice of a secured Web-based questionnaire that allowed rapid data collection [94]. Web-based health-related research has advantages in terms of feasibility [97] even though participation rates can vary [98]. An online questionnaire is known to allow rapid surveys following mass traumatic events and appears to reduce the risk of bias linked to social desirability [94], a bias that can be found in studies among hospital professionals questioned on their own health. However, a web-based questionnaire requires certain precautions. On the technical level, anonymity must be insured and technical difficulties anticipated and overcome [99]: for the ECHOS survey, anonymity was guaranteed thanks to a separate telephone number database, unrelated to identifiers, and independent from the data processing department; in case of technical difficulties accessing the questionnaire, a telephone number was available to quickly solve the problem. On the epidemiological level, due to potential selection bias of respondents, as the questionnaire was accessible online, individuals not part of the hospital staff were theoretically able to access it. To limit this possibility, it was decided not to relay the information via the press so that awareness would be restricted to hospital personnel; furthermore, an initial filter screened the respondent in terms of eligibility.

A self-selection bias may have introduced a further limitation to the survey since individuals are inclined to favour questionnaires that relate to their personal experience [100], such as those exposed to the consequences of a terror attack, while those not exposed may have felt unconcerned by the survey. Conversely, exposed and psychologically affected professionals may have been reluctant to take part in this type of research, which can lead to a lack of representativeness of the study population [94, 101]. Lastly, members of staff may have left the institution between the terror attack and June 2017. This could lead to a "healthy worker effect" selection type bias. Although we do not have any information on the number and profiles of employees who left hospital services since the date of the terror attack, it is likely that some of them have left because of their experience of the attack. This could lead us to underestimate our results.

To the extent that health-related activities usually confront hospital professionals with numerous causes for stress, predisposing them to psychological risks and burnout [80, 102-104], provision of care to victims of a terror attack is an extremely violent event that intensifies these health-related risks. Such an impact on hospital professionals may go beyond simple health repercussions to compromise quality of care, risk of work stoppage and turnover of affected teams [11, 105, 106], an issue which should be of particular concern for institution managers. However, institutions lack clear instructions in terms of procedures and interventions to be implemented in favour of employees that are victims of a trauma event [107]. This study aims to contribute recommendations so that in case of collective events of a magnitude comparable to the Nice terror attack the consequences of its impact on health professionals exposed to critical situations may be anticipated and allow appropriate decisions to be made in due time $[87,108]$.

\section{Abbreviations}

A\&E: Accident and emergency; HAD: Hospital anxiety and depression scale; OTP: One-Time Password; PCL5: PTSD Checklist for DSM V; PTSD: Posttraumatic stress disorder

\section{Acknowledgements}

The authors sincerely thank all those who accepted to be involved in this study: Santé Publique France, for their expertise and contribution; Mr. C. GUEPRATTE, managing director of Nice University Hospital; Mr. A. POUILLART, managing director of the Fondation Lenval; the members of the scientific committee: Mrs. K. HAMELA (Human Resources director), Pr M. BENOIT (Psychiatry, Nice CHU), Dr. J.H. PLANCHARD (Occupational medicine, Nice CHU); all those who contributed to the development and implementation of the study: members of the Nice $\mathrm{CHU}$ and Fondation Lenval managing department, members of staff who took part in testing the questionnaire, staff of Nice CHU Public Health department, Nice CHU and Lenval departments.

The authors particularly wish to thank the respondents of the ECHOS de Nice study, Nice CHU and Lenval health professionals and students who gave their time and accepted to share their experience in this distressing context.

\section{Authors' contributions}

$L B, P R$, YM, SV, TB, RF, PTL, and CP designed the study protocol. LB, PP, YM, SV, TB and PTL developed the questionnaire. LB, PR, YM, SV, TB, PTL and CP drafted the manuscript. All authors made substantial contributions to conception and design. All authors have read and approved the final manuscript.

\section{Funding}

This study was supported by the Regional Health Agency for Provence-AlpesCôte d'Azur (Agence Régionale de Santé) who provided Nice University Hospital with financial support to identify and retribute a psychologist specialized in psychological trauma to care for exposed hospital staff, and by the Fondation de France: « Ensemble face au terrorisme » (Together against terrorism) Committee who funded the data collection and management tool.

Availability of data and materials

Data are currently undergoing analysis.

\section{Ethics approval and consent to participate}

Ethical approval for the trial was obtained from the National Ethics Committee for Human Research (RCBID N ${ }^{\circ}$ 2017-A00812-51). Participants consented to participate in the study, the procedures required to participate and access the online questionnaire were considered as consent to take part in the survey. Prior to completing the survey, eligibility was checked via an online inclusion questionnaire followed by a written request for respondents' consent to participate.

Consent for publication

Not applicable.

Competing interests

The authors declare that they have no competing interests. 
In the past 5 years, they did not receive reimbursements, fees, funding or salary from an organization that may in any way gain or lose financially from the publication of this manuscript, either now or in the future.

They do not hold any stocks or shares in an organization that may, in any way, gain or lose financially from the publication of this manuscript, either now or in the future.

They do not hold or are not currently applying for any patents relating to the content of the manuscript.

They did not receive reimbursements, fees, funding or salary from an organization that holds or has applied for patents relating to the content of the manuscript.

They do have any other financial competing interests.

There are no non-financial competing interests (political, personal, religious, ideological, academic, intellectual, commercial or any other) associated with this manuscript.

\section{Author details}

${ }^{1}$ Public Health Department, Cote d'Azur University, Nice University Hospital, F-06200 Nice, France. ${ }^{2}$ Non-communicable Diseases and Trauma Division, French National Public Health Agency (Santé Publique France), F-94415 Saint-Maurice, France. ${ }^{3}$ Epidemiology and Population Health Research Centre (CESP), National Health and Medical Research Institute (INSERM), Unit 1178 "Santé Mentale et Santé Publique", F-94807 Villejuif Cedex, France. ${ }^{4}$ Department of Social Epidemiology, National Health and Medical Research Institute (INSERM), Pierre Louis Institute of Epidemiology and Public Health (IPLESP), Sorbonne University ${ }_{\mu}$ F75012 Paris, France. ${ }^{5}$ French National Public Health Agency (Santé Publique France), Regional Office of Nouvelle Aquitaine, F-94415 Saint-Maurice, France. ${ }^{6}$ Paris-Seine-Saint-Denis University Hospitals (AP-HP), Hôpital Avicenne, Paris 13 University, F-93000 Bobigny, France. ${ }^{7}$ National Resources and Resilience Centre (CNRR), F-93000 Bobigny, France. ${ }^{8}$ CoBTeK lab, Nice University Hospital, CMRR, Cote d'Azur University, F-06200 Nice, France.

Received: 7 May 2019 Accepted: 13 August 2019

Published online: 23 August 2019

\section{References}

1. Carles M, Levraut J, Gonzalez JF, Valli F, Bornard L. Mass casualty events and health organisation: terrorist attack in Nice. Lancet. 2016;388(10058):2349-50.

2. Gonzalez JF, Thomas J, Raynier J-L, De Peretti F, Trojani C, Carles M, et al. Attentat du 14 juillet 2016 à Nice : organisation et prise en charge des lésions ostéoarticulaires. Attack of July 142016 in Nice: Organization and management of osteoarticular lesions. Rev Chir Orthopédique Traumatol. 2017;103(7 (Supplement)):S131.

3. Askenazy F. Paradis perdu. Neuropsychiatr Enfance Adolesc. 2017;65(5):273-77.

4. Norris FH. Psychosocial consequences of disasters. Natl Cent Post-Trauma Stress Disord. 2002;13(2) Spring. Available on: www.ptsd.va.gov/professional/ newsletters/research-quarterly/v13n2.pdf.

5. Brooks SK, Chalder T, Gerada C. Doctors vulnerable to psychological distress and addictions: treatment from the practitioner health Programme. J Ment Health. 2011;20(2):157-64.

6. Wisnivesky JP, Teitelbaum SL, Todd AC, Boffetta P, Crane M, Crowley L, et al. Persistence of multiple illnesses in World Trade Center rescue and recovery workers: a cohort study. Lancet. 2011;378(9794):888-97.

7. Yip J, Webber MP, Zeig-Owens R, Vossbrinck M, Singh A, Kelly K, et al. FDNY and 9/11: Clinical services and health outcomes in World Trade Centerexposed firefighters and EMS workers from 2001 to 2016. Am J Ind Med. 2016;59(9):695-708.

8. Vandentorren S, Pirard P, Sanna A, Aubert L, Motreff Y, Vuillermoz C, et al. Psychological, somatic and social impact on people involved in terror attacks in January 2015 in Paris: results of the IMPACTS study. Poster, International Society for Traumatic Stress Studies. Chicago: ISTSS; 2017. (ISTSS 33rd Annual Meeting)

9. Vandentorren S, Pirard P, Sanna S, Aubert I, Motreff Y, Dantchev N, et al. Healthcare provision and the psychological, somatic and social impact on people involved in the terror attacks in January 2015 in Paris: cohort study. Br J Psychiatry. 2018;212(4):207-14.

10. Motreff $Y$, Pirard $P$, Baubet $T$, Chauvin $P$, Vandentorren S. Enquête de santé publique post-attentats du 13 novembre 2015 (ESPA 13-Novembre): premiers résultats concernant les intervenants. Bull Epidemiol Hebd. 2018; 38-39:756-64.
11. De Boer J, Lok A, Van Verlaat E, Duivenvoorden HJ, Bakker AB, Smit BJ. Work-related critical incidents in hospital-based health care providers and the risk of post-traumatic stress symptoms, anxiety, and depression: a metaanalysis. Soc Sci Med. 2011;73:316-26.

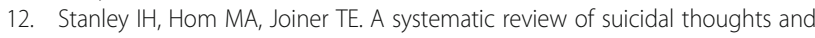
behaviors among police officers, firefighters, EMTs, and paramedics. Clin Psychol Rev. 2016;44:25-44.

13. Krysinska K, Lester D. Post-traumatic stress disorder and suicide risk: a systematic review. Arch Suicide Res. 2010;14(1):1-23.

14. Gradus JL, Qin P, Lincoln AK, Miller M, Lawler E, Sørensen HT, et al. Posttraumatic stress disorder and completed suicide. Am J Epidemiol. 2010;171(6):721-7.

15. American Psychiatric Association (APA). Diagnostic and statistical manual of mental disorders (DSM-5 ${ }^{\oplus}$ ). 5th ed. Airlington: American Psychiatric Association; 2013.

16. Breslau N, Davis GC, Andreski P. Traumatic events and posttraumatic stress disorder in an urban population of young adults. Arch Gen Psychiatry. 1991; 48(3):216-22.

17. Chidiac N, Crocq L. Le psychotrauma. Stress et trauma. Considérations historiques. Ann Méd Psychol. 2010;168:311-9.

18. Levin AP, Kleinman SB, Adler JS. DSM-5 and posttraumatic stress disorder. J Am Acad Psychiatry Law. 2014;42(2):146-58.

19. Sareen J. Posttraumatic Stress Disorder in Adults: Impact, Comorbidity, Risk Factors, and Treatment. Can J Psychiatry. 2014;59(9):460-7.

20. Perrin MA, DiGrande L, Wheeler K, Thorpe L, Farfel M, Brackbill R. Differences in PTSD prevalence and associated risk factors among world trade center disaster rescue and recovery workers. Am J Psychiatry. 2007;164(9):1385-94.

21. Berger W, Coutinho ESF, Figueira I, Marques-Portella C, Luz MP, Neylan TC, et al. Rescuers at risk: a systematic review and meta-regression analysis of the worldwide current prevalence and correlates of PTSD in rescue workers. Soc Psychiatry Psychiatr Epidemiol. 2012;47(6):1001-11.

22. Fullerton CS, Ursano RJ, Wang L. Acute stress disorder, posttraumatic stress disorder, and depression in disaster or rescue workers. Am J Psychiatry. 2004;161(8):1370-6.

23. Wilson LC. A systematic review of probable posttraumatic stress disorder in first responders following man-made mass violence. Psychiatry Res. 2015; 229(1-2):21-6.

24. Skogstad L, Heir T, Hauff E, Ekeberg $\varnothing$. Post-traumatic stress among rescue workers after terror attacks in Norway. Occup Med. 2016;66(7):528-35.

25. Vandentorren S, Pirard P, Sanna A, Aubert L, Motreff Y, Vuillermoz C, et al. Étude IMPACTS: Investigation des manifestations traumatiques postattentats et de la prise en charge thérapeutique et de soutien des personnes impliquées dans les attentats de janvier 2015 en Île-de-France. Bull Epidemiol Hebd. 2018;38-39:738-46.

26. De Stefano C, Orri M, Agostinucci JM, Zouaghi H, Lapostolle F, Baubet T, et al. Early psychological impact of Paris terrorist attacks on healthcare emergency staff: a cross-sectional study. Depress Anxiety. 2018;35:275-82.

27. North CS, Suris AM, Davis M, Smith RP. Toward validation of the diagnosis of posttraumatic stress disorder. Am J Psychiatry. 2009;166(1):34-41.

28. Guesnier E. Le regard d'un cadre de santé Sur l'organisation des soins le 14 juillet 2016, soir de l'attentat de Nice reflections of a help-care manager on emergency care provided following the 14 July 2016 attack in Nice. Neuropsychiatr Enfance Adolesc. 2017;65:278-80.

29. Stamm BH. The Concise ProQOL Manual. 2nd ed. Pocatello; 2010. Available on: CompassionSatisfactionAndCompassionFatigue.com / Proqol.org

30. McLaughlin KA, Koenen KC, Friedman MJ, Ruscio AM, Karam EG, Shahly V, et al. Sub-threshold post traumatic stress disorder in the WHO World Mental Health Surveys. Biol Psychiatry. 2016;77(4):375-84.

31. Weiss DS, Marmar CS, Schlenger WE, Fairbank JA, Jordan BK, Hough RL, et al. The prevalence of lifetime and partial post-traumatic stress disorder in Vietnam theater veterans. J Trauma Stress. 1992;5(3):365-76.

32. Stein MB, Walker JR, Hazen AL, Forde DR. Full and partial posttraumatic stress disorder: findings from a community survey. Am J Psychiatry. 1997; 154(8):1114-9.

33. Lai T-J, Chang C-M, Connor KM, Lee L-C, Davidson JRT. Full and partial PTSD among earthquake survivors in rural Taiwan. J Psychiatr Res. 2004;38(3):313-22.

34. Franklin $\mathrm{CL}$, Raines $\mathrm{AM}$, Chambliss JL, Walton JL, Maieritsch KP. Examining various subthreshold definitions of PTSD using the Clinician Administered PTSD Scale for DSM-5. J Affect Disord. 2018;234:256-60.

35. Marshall RD, Olfson M, Hellman F, Blanco C, Guardino M, Struening EL. Comorbidity, impairment, and suicidality in subthreshold PTSD. Am J Psychiatry. 2001;158(9):1467-73. 
36. Figley CR. Compassion fatigue: psychotherapists' chronic lack of self care. J Clin Psychol. 2002;58(11):1433-41.

37. Adams RE, Boscarino JA, Figley CR. Compassion fatigue and psychological distress among social workers: a validation study. Am J Orthopsychiatry. 2006;76(1):103-8.

38. Vlahov D, Galea S, Ahern J, Resnick H, Boscarino JA, Gold J, et al. Consumption of cigarettes, alcohol, and marijuana among new York City residents six months after the September 11 terrorist attacks. Am J Drug Alcohol Abuse. 2004;30(2):385-407.

39. Nandi A, Galea S, Ahern J, Vlahov D. Probable cigarette dependence, PTSD, and depression after an urban disaster: results from a population survey of new York City residents 4 months after September 11, 2001. Psychiatry. 2005;68(4):299-310.

40. Bills CB, Levy NAS, Sharma V, Charney DS, Herbert R, Moline J, et al. Mental health of workers and volunteers responding to events of 9/11: Review of the literature. Mt Sinai J Med. 2008;75(2):115-27.

41. Bogstrand ST, Skogstad L, Ekeberg $\varnothing$. The association between alcohol, medicinal drug use and post-traumatic stress symptoms among Norwegian rescue workers after the 22 July twin terror attacks. Int Emerg Nurs. 2016;28:29-33.

42. DiMaggio C, Galea S, Li G. Substance use and misuse in the aftermath of terrorism. A Bayesian meta-analysis. Addiction. 2009;104(6):894-904.

43. Jordan HT, Miller-Archie SA, Cone JE, Morabia A, Stellman SD. Heart disease among adults exposed to the September 11, 2001 World Trade Center disaster: Results from the World Trade Center Health Registry. Prev Med. 2011;53(6):370-6.

44. Jordan HT, Stellman SD, Morabia A, Miller-Archie SA, Alper H, Laskaris Z, et al. Cardiovascular disease hospitalizations in relation to exposure to the September 11, 2001 World trade center disaster and posttraumatic stress disorder. J Am Heart Assoc Cardiovasc Cerebrovasc Dis. Available on: http:// www.ncbi.nlm.nih.gov/pmc/articles/PMC3835258/.

45. Miller-Archie SA, Jordan HT, Ruff RR, Chamany S, Cone JE, Brackbill RM, et al. Posttraumatic stress disorder and new-onset diabetes among adult survivors of the World Trade Center disaster. Prev Med. 2014;66:34-8.

46. Giosan C, Malta LS, Wyka K, Jayasinghe N, Evans S, Difede J, et al. Sleep disturbance, disability, and posttraumatic stress disorder in utility workers. J Clin Psychol. 2015;71(1):72-84.

47. Brackbill RM, Cone JE, Farfel MR, Stellman SD. Chronic physical health consequences of being injured during the terrorist attacks on World Trade Center on September 11, 2001. Am J Epidemiol. 2014;179(9):1076-85.

48. Gupta MA. Review of somatic symptoms in post-traumatic stress disorder. Int Rev Psychiatry. 2013;25(1):86-9.

49. Stough LM, McAdams DE, Holt JM. Changes in the social relationships of individuals with disabilities displaced by disaster. Int J Disaster Risk Reduct. 2017;24:474-81.

50. Plat MC, Westerveld GJ, Hutter RC, Olff M, Frings-Dresen MH, Sluiter JK Return to work: police personnel and PTSD. Work. 2013;46(1):107-11.

51. Pirard $P$, Motreff $Y$, Lavalette $C$, Vandentorren $S$, Baubet $T$, Messiah A Enquête de santé publique post-attentats du 13 novembre 2015 (ESPA 13Novembre): trouble de santé post-traumatique, impact psychologique et soins, premiers résultats concernant les civils. Bull Epidemiol Hebd. 2018;3839:747-55.

52. Lemieux V. «Pour qu'on se comprenne », Guide de littératie en santé. Québec: Direction de santé publique, Agence de la santé et des services sociaux de Montréal, Secteur Services préventifs en milieu clinique; 2014. p. 72. Available on: https://santemontreal.qc.ca/professionnels/drsp/ publications/publication-description/publication/pour-quon-se-comprenneguide-de-litteratie-en-sante/

53. Ben-Ezra M, Palgi Y, Wolf JJ, Shrira A. Psychiatric symptoms and psychosocial functioning among hospital personnel during the Gaza war: a repeated cross-sectional study. Psychiatry Res. 2011;189:392-5.

54. Collins S, Long A. Working with the psychological effects of trauma: consequences for mental health-care workers--a literature review. J Psychiatr Ment Health Nurs. 2003;10(4):417-24.

55. Misra M, Greenberg N, Hutchinson C, Brain A, Glozier N. Psychological impact upon London ambulance service of the 2005 bombings. Occup Med. 2009;59(6):428-33.

56. Alexander DA, Klein S. Ambulance personnel and critical incidents: impact of accident and emergency work on mental health and emotional wellbeing. Br J Psychiatry. 2001;178(1):76-81.

57. Donnelly $E$, Siebert D. Occupational risk factors in the emergency medical services. Prehosp Disaster Med. 2009;24(5):422-9.
58. Adriaenssens J, de Gucht V, Maes S. The impact of traumatic events on emergency room nurses: Findings from a questionnaire survey. Int I Nurs Stud. 2012;49(11):1411-22.

59. Lebigot F. In: Ingberg H, editor. Le traumatisme psychique. Bruxelles: Ministère de la Communauté française; 2006. p. 34. Available on: http:// www.yapaka.be/files/ta_trauma_psychique.pdf.

60. Brooks SK, Dunn R, Amlôt R, Greenberg N, Rubin GJ. Social and occupational factors associated with psychological distress and disorder among disaster responders: a systematic review. BMC Psychol. 2016:4(1):18.

61. Bracha HS, Williams AE, Haynes SN, Kubany ES, Ralston TC, Yamashita JM. The STRS (shortness of breath, tremulousness, racing heart, and sweating): a brief checklist for acute distress with panic-like autonomic indicators; development and factor structure. Ann Gen Hosp Psychiatry. 2004;3:8.

62. Birmes $P$, Brunet A, Benoit M, Defer S, Hatton L, Sztulman H, et al. Validation of the peritraumatic dissociative experiences questionnaire self-report version in two samples of French-speaking individuals exposed to trauma. Eur Psychiatry. 2005;20(2):145-51.

63. Bryant RA. Predicting posttraumatic stress disorder from acute reactions. J Trauma Dissociation. 2005:6(2):5-15.

64. Hamilton MA. The assessment of anxiety states by rating. Bristish J Med Psychol. 1959;32(1):50-55.

65. Zigmond AS, Snaith RP. The hospital anxiety and depression scale. Acta Psychiatr Scand. 1983;67(6):361-70.

66. Bjelland I, Dahl AA, Haug TT, Neckelmann D. The validity of the Hospital Anxiety and Depression Scale. J Psychosom Res. 2002;52(2):69-77.

67. Thompson E. Hamilton rating scale for anxiety (HAM-A). Occup Med. 2015;65:601.

68. Maslach C, Jackson SE. The measurement of experienced burnout. J Occup Behav. 1981;2:99-113.

69. Ashbaugh AR, Houle-Johnson S, Herbert C, El-Hage W, Brunet A. Psychometric validation of the english and french versions of the posttraumatic stress disorder checklist for DSM-5 (PCL-5). PLoS ONE. 2016; 11(10) Cité 1 sept 2017. Available on: http://www.ncbi.nlm.nih.gov/pmc/ articles/PMC5056703/.

70. Blevins CA, Weathers FW, Davis MT, Witte TK, Domino JL. The posttraumatic stress disorder checklist for DSM-5 (PCL-5): development and initial psychometric evaluation. J Trauma Stress. 2015;28(6):489-98.

71. North CS, Surís AM, Smith RP, King RV. The evolution of PTSD criteria across editions of DSM. Ann Clin Psychiatry. 2016;28(3):197-208.

72. Pai A, Suris AM, North CS. Posttraumatic stress disorder in the DSM-5: controversy, change, and conceptual considerations. Behav Sci. 2017;7(1):7.

73. Jehel L, Paterniti S, Brunet A, Duchet C, Guelfi JD. Prediction of the occurrence and intensity of post-traumatic stress disorder in victims 32 months after bomb attack. Eur Psychiatry. 2003;18(4):172-6.

74. Luce A, Firth-Cozens J, Midgley S, Burges C. After the Omagh bomb: posttraumatic stress disorder in health service staff. J Trauma Stress. 2002; 15(1):27-30.

75. Laal M, Aliramaie N. Nursing and coping with stress. Int J Collab Res Intern Med Public Health. 2010;2(5):168-81.

76. McFarlane AC, Bryant RA. Post-traumatic stress disorder in occupational settings: anticipating and managing the risk. Occup Med. 2007;57:404-10.

77. North CS, Tivis L, McMillen JC, Pfefferbaum B, Spitznagel EL, Cox J, et al. Psychiatric disorders in rescue workers after the Oaklahoma City bombing. Am J Psychiatry. 2002;159(5):857-9.

78. Morris MC, Rao U. Psychobiology of PTSD in the acute aftermath of trauma: integrating research on coping, HPA function and sympathetic nervous system activity. Asian J Psychiatr. 2013;6(1):3-21.

79. Grieger TA, Fullerton CS, Ursano RJ. Posttraumatic stress disorder, depression, and perceived safety 13 months after September 11. Psychiatr Serv. 2004;55(9):1061-3.

80. Firth-Cozens J, Midgley SJ, Burges C. Questionnaire survey of post-traumatic stress disorder in doctors involved in the Omagh bombing. Br Med J. 1999; 319(7225):1609.

81. Koren D, Caspi Y, Leiba R, Bloch D, Vexler B, Klein E. Acute stress reactions among medical and non-medical personnel in a general hospital under missile attacks. Depress Anxiety. 2009;26(2):123-8.

82. Lavoie S, Talbot LR, Mathieu L. Post-traumatic stress disorder symptoms among emergency nurses: their perspective and a 'tailor-made' solution. J Adv Nurs. 2011;67(7):1514-22.

83. Fernandes CMB, Bouthillette F, Raboud JM, Bullock L, Moore CF, Christenson JM, et al. Violence in the emergency department: a survey 
of health care workers. Can Med Assoc J J L'Association Medicale Can. 1999;161(10):1245-8.

84. Battles. An exploration of post-traumatic stress disorder in emergency nurses following Hurricane Katrina. J Emerg Nurs. 2007;33:314-8.

85. Sheehan DV, Harnett-Sheehan K, Raj BA. The measurement of disability. Int Clin Psychopharmacol. 1996;11(Suppl 3):89-95.

86. Healy S, Tyrrell M. Stress in emergency departments: experiences of nurses and doctors. Emerg Nurse. 2011:19(4):31-7.

87. Lucchini RG, Hashim D, Acquilla S, Basanets A, Bertazzi PA, Bushmanov A, et al. A comparative assessment of major international disasters: the need for exposure assessment, systematic emergency preparedness, and lifetime health care. BMC Public Health. 2019; Available on: http://www.ncbi.nlm.nih. gov/pmc/articles/PMC5219808/.

88. Gjerland A, Pedersen MJ, Ekeberg $\varnothing$, Skogstad L. Sick-leave and help seeking among rescue workers after the terror attacks in Norway, 2011. Int J Emerg Med. 2015;8(1):81.

89. Tyssen R. Health problems and the use of health services among physicians: a review article with particular emphasis on Norwegian studies. Ind Health. 2007:45(5):599-610.

90. Cohen D, Winstanley SJ, Greene G. Understanding doctors' attitudes towards self-disclosure of mental ill health. Occup Med. 2016;66:383-9.

91. Thompson WT, Cupples ME, Sibbett CH, Skan DI, Bradley T. Challenge of culture, conscience, and contract to general practitioners' care of their own health: qualitative study. Br Med J. 2001;323:728-31.

92. Mourgues JM, Lebreton-Lerouvillois G, Bissonnier C, Boetsch D. La santé des étudiants et jeunes médecins. Conseil National de l'Ordre des Médecins COMMISSION JEUNES MÉDECINS - SECTION SANTÉ PUBLIQUE ET DÉMOGRAPHIE MÉDICALE; 2016. Available on : https://www.conseil-national. medecin.fr/sites/default/files/sante_et_jeunes_medecins.pdf

93. Bolton P, Tol WA, Bass J. Combiner les méthodes de recherche qualitatives et quantitatives pour appuyer des programmes psychosociaux et de santé mentale dans des situations d'urgence complexes. Introduction à cette édition spéciale. Résumés en Français. Intervention. 2009;7(3):283-5.

94. Schlenger WE, Silver RC. Web-based methods in terrorism and disaster research. J Trauma Stress. 2006;19(2):185-93.

95. Légifrance. Arrêté du 2 décembre 2016 fixant la liste des recherches mentionnées au $2^{\circ}$ de l'article L $1121-1$ du code de la santé publique. Version consolidée du 4 janvier 2017. Code de la Santé Publique. Partie législative. Première partie: Protection générale de la santé. Livre ler : protection des personnes en matière de santé. Titre II : recherches impliquant la personne humaine. Disponible sur: https://www. recherchecliniquepariscentre.fr/wp-content/uploads/2017/01/CSP_legislatif_ Titre-II_20170104_CFA.pdf

96. Santiago PN, Ursano RJ, Gray CL, Pynoos RS, Spiegel D, Lewis-Fernandez R, et al. A systematic review of PTSD prevalence and trajectories in DSM-5 defined trauma exposed populations: intentional and non-intentional traumatic events. PLoS One. 2019; Available on: https://journals.plos.org/ plosone/article?id=10.1371/journal.pone.0059236.

97. Herbert C, Brunet A. Psychotraumatismes: Quel rôle pour internet ? Stress Trauma. 2009;9(1):55-64.

98. Grieger TA, Fullerton CS, Ursano RJ, Reeves JJ. Acute stress disorder, alcohol use, and perception of safety among hospital staff after the sniper attacks. Psychiatr Serv. 2003:54(10):1383-7.

99. Eysenbach $G$, Wyatt J. Using the internet for surveys and Health Research. J Med Internet Res. 2002;4(2):e13.

100. Wyatt JC. When to use web-based surveys. J Am Med Inform Assoc. 2000; 7(4):426-9.

101. Stene LE, Dyb G. Research participation after terrorism: an open cohort study of survivors and parents after the 2011 Utøya attack in Norway. BMC Res Notes. 2019; Available on: http://www.ncbi.nlm.nih.gov/pmc/articles/ PMC4736239/.

102. Firth-Cozens J. Doctors, their wellbeing, and their stress. Br Med J. 2003; 326(7391):670-1.

103. McNeely $E$. The consequences of job stress for nurses' health: time for a check-up. Nurs Outlook. 2005;53:91-299.

104. McVicar A. Workplace stress in nursing: a literature review. J Adv Nurs. 2003; 44(6):633-42.

105. Elfering A, Semmer NK, Grebner K. Work stress and patient safety: Observerrated work stressors as predictors of characteristics of safety-related events reported by young nurses. Ergonomics. 2006;49(5-6: Patient safety):457-69.
106. Laposa JM, Alden LE, Fullerton LM. Work stress and posttraumatic stress disorder in ED nurses/personnel (CE). J Emerg Nurs. 2003;29(1):23-8.

107. Tehrani N. Workplace trauma and the law. J Trauma Stress. 2002;15(6):473-7.

108. Reissman DB, Howard J. Responder safety and health: preparing for future disasters. Mt Sinai J Med. 2008;75(2):135-41.

\section{Publisher's Note}

Springer Nature remains neutral with regard to jurisdictional claims in published maps and institutional affiliations.

\section{Ready to submit your research? Choose BMC and benefit from:}

- fast, convenient online submission

- thorough peer review by experienced researchers in your field

- rapid publication on acceptance

- support for research data, including large and complex data types

- gold Open Access which fosters wider collaboration and increased citations

- maximum visibility for your research: over $100 \mathrm{M}$ website views per year

At BMC, research is always in progress.

Learn more biomedcentral.com/submissions 